\title{
ASSESSING THE AFRICAN PEACE AND SECURITY ARCHITECTURE (APSA) FROM AN INSTITUTIONALIST APPROACH AND THE DIFFERENCE IT HAS MADE IN AFRICA SINCE 2002
}

\author{
Juliana Abena Appiah ${ }^{1}$
}

\section{Introduction}

The African Union (AU) was formed out of the Organization of African Unity (OAU) in July 2002 to tackle the myriad of challenges facing Africa. The I990s had been marked with several conflicts within the continent, which obviously had disturbed the peace, security and stability in Africa. The new AU was thus borne out of a consciousness of the fact that the scourge of conflicts in Africa constitutes a major impediment to the socioeconomic development of the continent, and therefore, there was the need to promote peace, security and stability as a prerequisite for the implementation of Africa's development and integration agenda. To that effect, the AU was prepared to commit to strengthening its institutions and providing them with the necessary powers and resources to enable them discharge their respective mandates effectively. Therefore, the AU set up its African Peace and Security Architecture (APSA) starting with the Peace and Security Council (PSC) the flagship institution in the APSA, in December 2003. The remaining components, which were added later, were the Continental Early Warning System (CEWS), the Panel of the Wise (PoW), the African Standby Force (ASF) and the African Peace Fund (APF). In addition, the AU Commission was to provide advisory support to the PSC and the rest of the components of the APSA.

I Legon Centre For International Affairs, University Of Ghana, Accra, Ghana. E-mail: jappiah@ug.edu.gh. 
The APSA is built around structures, objectives, principles and values, as well as decision-making processes relating to the prevention, management and resolution of crises and conflicts, post-conflict reconstruction and development in the continent. The APSA's work, therefore, is to uphold the AU's rules, norms, objectives and principles on peace, security and stability, and to ensure that the behavior of Member States conforms to them. Within the framework of the neo-Institutionalist theory of integration, and with the use of secondary data, the paper hypothesis that the APSA is disadvantaged as a result of not fairly applying its rules across the board in Member States. The paper assesses the performance of the APSA since its inception. The major objective of the paper is to ascertain whether the APSA has made any difference in the area of peace, security and stability since it came to being. Has the APSA been institutionalized fully? Is it functioning as expected? If not, what are the daunting constraints, and how can they be addressed to enable the APSA function to its full capacity and expectation? The paper is made up of seven sections: Introduction; The New Institutionalist Theory; The AU and the APSA; Analysis of the Legal Framework of the APSA; Assessment of the APSA; The APSA: What Difference in Africa?; and the Conclusion.

\section{The New Institutionalist Theory}

The new Institutionalist theory of integration is a build-up of the traditional Institutionalist theory. The former seeks to improve on the latter by prescribing particular ways in which to apply the theory. In political science and international relations, institutionalism was applied to the study of constitutions, legal systems and government structures. Institutionalism emerged as a reaction to the under-socialized character of the dominant approaches in political science. The theory has, over the years, gained grounds in the social sciences, and it is used for analyses of both micro interpersonal as well as macro global systems.

Stephen Bell defines an institution "as a process or set of processes which shape behaviour." He also quotes a dictionary definition of an institution as "established law, custom or practice." According to Bell, institutions matter because laws, customs and established practices in institutional and organizational settings can play a powerful role in shaping the behaviour of individuals. Institutions may be formal or informal, and the most effective institutional arrangements are the ones which incorporate a normative system of informal and internalized rules. Institutionalism therefore emphasizes how institutional constraints in the form of rules, conventions, norms and codes 
of behaviour contribute in shaping the power, behaviour and preferences of actors, and which in turn shape policy outcomes. These are the premises on which new institutionalism is built.

There are three major variants of new institutionalism: rational choice, sociological (normative) and historical. However, five core assumptions form the foundation of the whole school of new institutionalism. First of all, institutions create order and predictability such that political actors are constrained to act within the logic of appropriateness. Institutions reflect a polity's character, identity, history and vision, and they provide affinity ties, which bind actors together in spite of the differences among them. Secondly, institutions generate structures, which are translated into political action, and political action in turn results in institutional continuity and change. Thirdly, a collection of institutions, which fit into a coherent system produce political order. Actors organize themselves and act in accordance with rules and practices, which are socially constructed, publicly known, anticipated and accepted. Institutions define basic rights and responsibilities of actors, and regulate how advantages, burdens and life-choices are allocated in society. Authority is also created to settle issues and resolve conflicts. The fourth assumption is that institutions give to social relations, reduce flexibility and variability in behaviour, and restrict the possibility of a one-sided pursuit of self-interest. The fundamental logic of action is rule following, that is, prescriptions based on the question of appropriateness. Rules are followed because they are seen by actors as natural, rightful, expected and legitimate. Members are expected to obey and be guardians of the institution's constitutive principles and standards. The last but not the least is that institutions are not static and irreversible. Institutions are defended by insiders and validated by outsiders, and because their histories are encoded into rules and routines, their internal structures and rules cannot be changed arbitrarily. Changes occurring are most likely to reflect the adaptation to local experience and thus be relatively myopic and meandering, rather than optimizing, as well as inefficient in the sense of not reaching a uniquely optimal arrangement.

\section{The AU and the APSA}

The Organization of African Unity (OAU) was transformed to the African Union (AU) due to the changes in political, peace and security, as well as socio-economic needs of Africa within the context of the broader global changes as a result of the end of the Cold War. The normative and institutional framework of the AU was shaped significantly by the expansion 
in the concept of security to encompass not only the narrow traditional (statecentered) sense, but also a broader human-centered conceptualization of security. The African Peace and Security Architecture (APSA) was to be the operational structure for the effective implementation of decisions taken on conflict prevention, peace-making, peace support operations, peace-building and post-conflict reconstruction. Its mandate also reflects the shift to human security, which is widely accepted at the continental level. It is to deal with issues related to human development, promote democratic practices, good governance and respect for human rights, and humanitarian action and manage disaster. Aside the AU Commission, which is to support its activities, the APSA is made up of five major components, namely; The Peace and Security Council (PSC), The Continental Early Warning Systems (CEWS), The Panel of the Wise (PoW), The African Standby Force (ASF), and The African Peace Fund (APF). Aside these, the APSA depend heavily on the AU Commission for administrative support.

\section{The Peace and Security Council}

The PSC succeeded the OAU Central Organ of the Mechanism for Conflict Prevention, Management and Resolution, the operational body that was mandated to make decisions on matters of peace and security. The PSC is the main pillar of the APSA. Through the PSC, the AU is able to work with the Regional Economic Communities (RECs) or Regional Mechanisms for Conflict Prevention, Management and Resolution (RMs) and by that, the RECs/RMs are made a part of the APSA. The PSC also interacts with other AU organs such as the Pan-African Parliament and the African Commission on Human and Peoples' Rights, civil society organizations, the United Nations (UN), and other relevant international stakeholders. These interactions have, however, not always been healthy. One source of tension that readily undermines effective cooperation between the AU and the RECs, which needs to be resolved if continental integration would speed up, is the overlap of roles and responsibilities. There is need to clearly restate the roles and responsibilities between the AU, its member States and the RECs. Doing this will ensure a decrease in tensions and so will the accusations of division and sectional conspiracy that often characterize the relationship between the AU and the RECs decrease. Clearly spelling out the different roles, responsibilities, obligations and corresponding institutional architecture in the Constitutive Act of the AU and treaties of the various RECs is also critical to the progress of this relationship. Fortunately, the Heads of State and Government of the AU have sanctioned a review of the Constitutive Act and it is hoped that these areas will be clarified. 
Returning to the PSC, it was specifically established to be a collective security and early warning arrangement with the ability to facilitate timely and efficient responses to conflict and crisis situations. It has the power to recommend intervention in Member States to promote peace, security and stability.

The PSC has fifteen members, who are all elected by the AU Executive Council for endorsement by the AU Assembly. Five Members are elected for three-year terms, usually to take up office on the first day of April, following endorsement by the Assembly. Retiring members are eligible for immediate re-election. Members are elected according to the principle of equitable regional representation and national rotation agreed within the regional groups: Central, Eastern, Northern, Southern, and Western Africa. The idea of regional representation, though laudable, has so far not helped the PSC as some countries have taken advantage of this rotation scheme time and again. Nigeria, as a case in point, has served on the PSC since its inception in 2004 and yet has consistently avoided election. Nigeria has succeeded in making itself a de facto permanent member of the PSC. This has been made possible due to Nigeria's preponderant power. Again, some member States elected to the PSC have, during their tenure, experienced violent conflicts and yet have remained members of the Council. Others have clearly not respected the principle of constitutionality, human rights, rule of law and good governance in general. All these cast serious doubts on the AU's commitment to democracy and good governance.

\section{The Continental Early Warning Systems (CEWS)}

The CEWS are responsible for data collection and analysis. It is mandated to collaborate with the $\mathrm{UN}$, its agencies, other relevant international organizations, Research Centres, academic institutions, and non-governmental organizations (NGOs). Its information is to be used by the Chairperson of the AU Commission to advise the PSC on potential conflicts and threats to peace and security in Africa, and recommend the best course of action.

The objective of the CEWS is to anticipate and prevent conflicts on the continent; and to provide timely information on evolving violent conflicts based on specifically developed indicators. It has six information-gathering tools: the Africa Media Monitor, Indicators and Profiles Module, Africa Reporter, CEWS Portal, Africa Prospectus, and the Live-Mon.

The CEWS are established by Article I2 of the PSC Protocol. Per the Protocol, the CEWS is made up of two components. First is the "Situation 
Room," an observation and monitoring centre located at the Conflict Management Division of the AU. It is in charge of data collection and analysis. Second are the observation and monitoring units of the RECs/RMs. They are to be linked directly through appropriate means of communication to the Situation Room. They are also to collect and process data at their level for onward transmission to the Situation Room.

In 2006, the Governmental Experts Meeting on Early Warning and Conflict Prevention adopted the Framework for the Operationalization of the CEWS. The Framework was later endorsed by the Executive Council in Addis Ababa in January 2007. The Council requested the Commission to see to the full implementation of the Framework within a timeframe of three years to make the CEWS fully operational.

\section{The Panel of the Wise}

The PoW is a critical pillar of the APSA. It is a five-person panel of highly respected African personalities from various segments of society who have made outstanding contribution to the cause of peace, security and development in the continent. They are to support efforts of the PSC and those of the Chairperson of the Commission, particularly in the area of conflict prevention. The first Panel was appointed in December 2007. Members of the Panel serve terms of three years, after which they are eligible for appointment for another term. The PoW reports to the Assembly through the PSC. Members are selected by the Chairperson of the AU Commission, and appointed through a decision of the Assembly. The Panel meets at least three times a year to deliberate on its work programme, and to identify regions and countries to visit. It also organizes annual workshops on issues related to conflict prevention and management to assist in producing a thematic report to be submitted to the Assembly for endorsement.

Article II of the PSC Protocol establishes the PoW. Its mandate is to support and advise the Chairperson of the Commission and the PSC in the area of conflict prevention; advise both on issues of impunity, justice and reconciliation, as well as women and children in armed conflicts; use its good offices to carry out conflict mediation and broker peace agreements between warring parties; and help the AU Commission to map out threats to peace and security by providing regular advice and analysis, and requesting the deployment of fact-finding and mediation teams to specific countries. 


\section{The African Standby Force}

The ASF is established by Article 4(h) of the AU Constitutive Act and Article I3 of the PSC Protocol. The Act gives the AU the right to intervene in Member States in the events of grave circumstances (including war crimes, genocide, and crimes against humanity). The ASF is to prosecute this agenda through standby arrangements with Africa's five sub-regions.

The ASF is made up of multidimensional capabilities, including military, police and civilian. These personnel are on standby in their countries of origin, ready for rapid deployment. The initial concept of the ASF was that of a quick reaction capacity which would enable Africans to respond swiftly to a crisis, unhampered by any heavy political and instrumental burdens. The functions of the ASF include the following: observation and monitoring of missions; other types of peace support operations; intervention in a member state in respect of grave circumstances or at the request of a member state to restore peace and security, in accordance with Articles 4(h) and 4(j) of the Constitutive Act. Other functions are preventive deployment to prevent disputes and conflicts from escalating, an ongoing violent conflict from spreading to neighboring areas or states, and the resurgence of violence after parties to conflict have reached an agreement; and peace-building, including post-conflict disarmament and demobilization; humanitarian assistance to alleviate the suffering of civilian populations in conflict areas and support efforts to address major natural disasters. It also performs any other function as may be mandated by the PSC or the Assembly.

\section{The African Peace Fund}

The African Peace Fund (APF) was established in June I993 as one of the operational tools to finance peace and security activities of the AU. It was borne out of a realization that contributions of Member States alone were not sufficient for the OAU to undertake its various responsibilities. The Peace Fund is made up of financial appropriations from the regular AU budget, including arrears of contributions, voluntary contributions from Member States and from other sources within Africa, including the private sector, civil society and individuals, as well as through appropriate fundraising activities.

Obviously, the AU has, by the APSA, set up institutions and structures to facilitate achievement of its objective to promote peace and security in Africa. What remains is for these institutions and structures to function optimally to deliver on their mandates. 


\section{The Legal Framework of the APSA: A New AU Normative Order for the APSA to Police?}

The institutionalization of the APSA by the AU stemmed from the realization of the fact that the scourge of conflicts in Africa was a major impediment to the socio-economic development of the continent. The old OAU had not been granted adequate powers to deal with these conflicts to position Africa on a path of peace and security, as well as socio-economic growth and development. Therefore, there was the need to take steps to promote peace, security and stability as a prerequisite for the implementation of Africa's development and integration agenda. For that reason, the AU pledged to take all necessary measures to strengthen its institutions and provide them with the necessary powers and resources to enable them discharge their respective mandates effectively.

A study of the objectives and principles of the AU, compared with those of the OAU, reveals a shift from an old OAU normative order designed to safeguard the individual sovereignty of states in Africa to a new AU normative order aimed at addressing not only the security of the African state, but also the security of the African people; from a culture of non-intervention and noninterference in the internal affairs of Member States to a norm of intervention and non-indifference. Among others, the objectives of the AU are to defend the sovereignty, territorial integrity and independence of its Member States; promote peace, security and stability in the continent; promote democratic principles and institutions, popular participation and good governance; and promote and protect human and peoples' rights in accordance with the African Charter on Human and Peoples' Rights and other relevant human rights instruments. To these ends, the principles of the AU include prohibition of the use of force or threat of force among Member States; non-interference in the internal affairs of other Member States; the right of the AU to intervene in a Member State in respect of grave circumstances such as war crimes, genocide and crimes against humanity; the right of Member States to request intervention from the AU to restore peace and security, as well as respect for democratic principles, human rights, the rule of law and good governance.

In all of the above, the APSA has a great role to play to ensure that AU Member State's behaviour conforms to the objectives and principles of the AU. The work of the PSC is inspired by the mandate of the UN Security Council, which is tasked with the primary responsibility of maintaining international peace and security, as well as the role the UN Charter assigns to regional arrangements in the maintenance of peace and security. 
The PSC Protocol expresses deep concern about the continued prevalence of armed conflicts in Africa, to which it attributes the socioeconomic decline in Africa, as well as the suffering of the civilian population. The Protocol, therefore, expresses the determination of Member States to enhance their capacity to address the scourge of conflicts on the continent, as well as ensure the AU plays a central role in the pursuit of peace, security and stability in the continent. To put this determination into action, the Protocol establishes the PSC as a standing decision-making organ for the prevention, management and resolution of conflicts. The PSC is expected to be a collective security and early warning arrangement to facilitate timely and efficient response to conflict and crisis situations in Africa. The AU Commission and the four other components of the APSA are to support the PSC in carrying out this mandate.

The mandate of the APSA, per the PSC Protocol, makes the PSC a replica of the UN Security Council for the AU. It constitutes the heartbeat of the AU when it comes to dealing with threats to peace and security in the continent. Like the UN Security Council, the PSC exists to enforce the rules, principles, and norms of the AU in the area of peace and security. To be able to carry out its responsibilities, the PSC is granted some powers by Member States. Among others, the PSC has the power to anticipate and prevent disputes and conflicts, as well as policies that may lead to genocide and crimes against humanity. The PSC also has the power to undertake peacemaking and peace-building functions to resolve conflicts where they have occurred. It also has the power to authorize the monitoring and deployment of peace support missions, and to recommend to the Assembly, intervention on behalf of the AU, in accordance with Article 4(h) of the Constitutive Act. Other powers of the PSC are to approve the modalities for intervention; institute sanctions against unconstitutional changes of government in Member States; implement the Common African Defence Policy; implement AU and regional instruments on combating terrorism; and to promote and develop a strong partnership for peace and security between the AU and the UN, and other relevant international organizations.

By endowing the PSC with the powers in Article 7, the AU delegates the PSC to handle issues on the peace and security of the continent, as is the case with the UN and its Security Council. Thus, the PSC is expected to have the massive support of the AU Member States in the execution of its functions aimed at creating and sustaining peace and security in Africa. The PSC is expected to work closely with the AU Commission, which is to perform an advisory role in this area. The PoW is to support efforts of the PSC in the area of conflict prevention. The CEWS are also to support the PSC through 
the performance of observation and monitoring functions. The ASF supports the PSC in the deployment of peace support missions and interventions. The Peace Fund is to provide the necessary financial support to the PSC in times of peace support operations and other operational activities related to peace and security. This said, the Peace Fund has so far suffered some donor constraints since its inception. A typical case in point was Japan's behavior during the Mali crisis where the AU was instructed by Japan not to withdraw from the Peace Fund to send troops to Mali for direct combat role except for peacekeeping (Observer Missions). Donors give various prescriptions on what the funds they provide can or cannot be used for. The AU and its PSC may on the other hand deem it necessary to use the fund provided differently, putting them at variance with its donors. Such constraints from donors, therefore, limit the AU and the PSC's reach in fulfilling their mandate.

\section{The APSA: Successes, Progress and Challenges}

The performance of the components of the APSA is mixed. While some have been operationalized fully, others have not. Again, even the fully operational components have their own challenges that hinder them from functioning optimally.

The PSC seems to have performed creditably, having convened several meetings to deliberate on issues of conflict and crisis situations far beyond expectation. It has also issued several communiqués and statements relating to Burundi, Central African Republic, Chad, Comoros, Cote d'Ivoire, Democratic Republic of Congo, Guinea, Guinea-Bissau, Kenya, Liberia, Madagascar, Mauritania, Niger, Rwanda, Somalia, South Sudan, Sudan, Togo, and Zimbabwe, among others. The PSC has also authorized sanctions against several Member States. It has authorized the deployment of peace missions in Burundi (2003), Sudan (2004), the Comoros (2006), and Somalia (2007). The PSC has demonstrated ability to draw attention to crisis situations in Africa and continues to function as one of the most important and powerful components of the APSA. The achievements of the PSC so far demonstrate the growing commitment of Member States to tackle conflicts on the continent. It also gives an indication of the fragility of the security situation of some of its members.

Kwesi Aning, however, notes that the PSC has not been able to apply its norms, values and principles equally to all Member States. This is, however, not a surprising occurrence. Examples can be cited of Togo, Mauritania, and Sudan where PSC norms have been applied differently. In 
Togo, it took the combined leadership of the ECOWAS and the AU to reverse the palace coup, which took place in February 2005. In Mauritania, however, a 'blanket' application of sanctions after the coup d'etat culminated in an inability to bring the desired change and a reversal of the military takeover. Mauritania proved difficult, in spite of its suspension from the AU and the broader international efforts to return the country to democratic government. Sudan was a very tough one for the PSC. It brought to light a unique challenge about how the AU's developing norms and principles should be applied. The PSC and the wider international community, for a very long time, failed to change the behaviour of Sudan.

Again, the interface between the PSC and similar organs in the RECs/RMs has been limited. Interaction between the PSC and other APSA components has not been optimal. This is partly because some of the components have not been operationalized. Institutional support to the PSC is also limited, although the set of activities have grown exponentially. The PSC Secretariat is overstretched because it supports both the PSC and some of its members with limited capacity in their embassies. The structures in the RECs face similar administrative support challenges.

Further, the CEWS have been able to automate data collection and reporting at an advanced level. However, operationalization is mixed at the level of the RECs/RMs. Whereas the ECOWARN and CEWARN are relatively advanced in automation of data collection and reporting, progress at the CENSAD, EAC, and COMESA has been slow. However, impressive progress has been made in the establishment of policy frameworks, specific concepts and approaches to early warning. There have also been moves to get civil society organizations (CSOs) and training institutions with interest in early warning, peace and security on board.

Conflict analysis and development of response options have not been the best. This is because there are a number of challenges with the collection, sharing and distribution of information among stakeholders. A clear collaborative framework needs to be done in strengthening relations between the CEWS at the AU and the early warning systems of the RECs. In terms of infrastructure, although significant effort has been put into the development of systems for the smooth running of the CEWS, there are still issues with the analytic capacity of staff, recruitment and development of the necessary technical expertise, deployment of the necessary tools for data collection and analysis, institutionalization of a standardized early warning system at the RECs, and establishing the necessary system for linking them to the CEWS at the AU Headquarters, as well as the legal and political framework for institutionalized relations with the RECs. 
The PoW, on its part, has had several meetings, both formal and informal, with stakeholders in peace and security. It has embarked on some country visits and observation and monitoring in conflict-affected areas. Compared to the other components, not much is known about the details of their activities. The Panel is only expected to issue public statements on its activities, and it has limited communication of its programmes and activities to only the numerous communiques it has issued since its operationalization. Every year, the PoW works with a particular thematic area covered in its mandate: Prevention of Election-Related Violence (2008); Impunity, Reconciliation and Healing (2009); and Women and Children in Armed Conflict (2010). The Panel holds periodic meetings with the PSC on its key thematic areas which inform the decision-making process of the PSC. A special meeting was held on "Women and Children in Armed Conflict in March 20I0. The PoW has also organized workshops in Nairobi, Kenya (November 2008), Monrovia, Liberia (May 2009), and Kinshasa, DRC (May 2010).

Although the PoW seems to be on course, there are still a number of issues to take care of. Meetings of the Panel with the PSC are more informal than formal. The two seem to be working parallel to each other, and only meeting in their collaboration with the Chairperson of the Commission. Again, members of the Panel seem to be working in an ad hoc manner, with each engaged in other activities outside the PoW. Sometimes, they are not available when needed to take care of conflict situations. The Panel also seems to be more interested in conflict prevention (that is democracy, governance, rule of law) than management and resolution. This is in spite of the fact that there is already a lot of attention in conflict prevention. The challenge of not knowing its activities in detail also hampers peace efforts. Other stakeholders are not let in on all the happenings in areas of operation of the PoW. To resolve these challenges the Panel must ensure that its conflict prevention activities are properly coordinated with the AU's other institutions that handle peace and security. There must exist a cordial working relationship between the Panel, the PSC, the Department of Political Affairs and the AUC in order to avoid the duplication of roles but ensure efficiency in the delivery of service. The PoW further needs to broaden its scope of operation to collaborate with similar structures and institutions at the RECs as well as civil society organizations in Africa that deal in peace and security.

Further, efforts to operationalize the ASF have registered good progress, albeit, the degree of progress varying from region to region. Progress in the development of a multidimensional concept for the ASF is one of the most remarkable to date. The Military and Police components have been put in place in all the REC's. However, the setting up of the civilian component 
remains challenging. With regards to this, the policy development angle has been well covered by the various REC's. What remain problematic are the disparities in the levels of implementation of these policies by the various REC's. There is also no binding framework between the AU and the RECs and their Member States, regarding contribution of troops. The AU would also need an advocacy plan to raise awareness about its existence and activities, as African awareness of the role of the ASF remains poor. It is hoped that lessons from past exercises like the 20I0 AMANI and practical experience from peace operations in Darfur (AMIS/UNAMID) and Somalia (AMISOM) will contribute to achieving Full Operational Capability.

An assessment of the Peace Fund reveals that it is small and precarious. In 2007, a high-level Audit of the AU concluded that there was cause for concern regarding the funding of peace operations in Africa. Less than Io\% of the regular budget of the AU is allocated to the Peace Fund. This is too small compared with the needs of peacekeeping activities of the continent. The assessed contributions to finance peacekeeping have not been done, and the reimbursement within six months of states contributing contingents to peace support operations, as provided for in the Protocol has not always been honored. Until these challenges are met, the APSA's work will continue to face financial challenges, a situation that perhaps a partnership with the UN and other international organizations can ameliorate. This partnership with the UN and other International Organisations, however, has its own challenges that the AU itself acknowledges. The disadvantages in the overdependence on donors or foreign partners for financial resources stem from donor restrictions on what such funds can and cannot be applied to in the context of peace and security. Another challenge with the overdependence on donors then becomes the ownership of the peace process on the continent. Can the AU and its member states claim ownership of the peace processes in Africa when foreigners pay to ensure the processes take place? Is the popular mantra of 'African solutions to African problems' then mere talk with no concrete backing financially from African States? The AU at its Special Summit in Tripoli (2009) stated that it was critical that Member States met their financial obligations so the organization's dependency on external aid could be reduced and sustainability and ownership could be guaranteed.

\section{The APSA: What Difference in Africa?}

So far, it is obvious that the APSA has been institutionalized, although some challenges persist. Its components have been duly established by the 
appropriate legal framework. Its functions are also well known to Member States of the AU. Since they have been established by and with the consent of these Member States, it is expected that they will support the APSA in the discharge of its duties. Support in this sense includes ensuring that their actions or behaviour conform to and do not undermine the rules, principles, norms and values the APSA is tasked to police. Where Member States falter or go contrary to these norms, their behaviour should be seen as unacceptable, and therefore, the APSA should be able to apply the appropriate sanctions as may be determined, also with the support of Member States. What difference then has the APSA made in peace and security in Africa? How effective have its actions been? What have been the outcomes? Do the responses of the APSA in crisis and conflict situations guarantee its continuity? What changes are there likely to happen within the APSA in the future?

The APSA puts the AU in a better posture for tackling conflicts and crisis in Africa than the OAU. The APSA has to some extent facilitated the AU's quest to promote peace and security through interventions ranging from shuttle diplomacy and mediation; observer missions; condemnation of unconstitutional governments; to the deployment of peace support operations. However, the results have not always been the same. There have been successes as well as failures. This section discusses the successes and failures of the APSA as well as what accounts for these outcomes.

In peace operations, the APSA has recorded some remarkable achievements as well as some failures. For example, the operations in Burundi (2003-2004) were said to be very successful, although there were latter challenges with regards to Disarmament, Demobilization, and Reintegration (DDR). Initial UN assessments of the Burundian situation proved the precarious nature of the conflict. However, the pragmatic posture and leadership of the AU culminated in the cessation of violence. The presence of the AU Mission in Burundi (AMIB) discouraged violence and served as deterrence to the factions in the conflict, until the AMIB handed over successfully to the UN Mission in Burundi (ONUB) in 2004. Again, the AU operations in the Comoros were successful, as they contributed to returning the country to democratic rule. The AU Mission for Support to the Elections in the Comoros (AMISEC, deployed in 2006) and later the AU Electoral and Security Assistance Mission to the Comoros (MAES) faced initial challenges due to their small numbers. Somehow, they managed to create the right atmosphere for elections to be held. However, it took a brutal AU military invasion to oust the rebel government, and to return the central government to power.

In Sudan and Somalia, the results were entirely different. In Sudan, the operations proved extremely difficult. Like Burundi, the situation in Sudan 
was precarious. However, the mandate of the AU Mission in Sudan (AMIS, deployed in 2004) was too restrictive to allow for robust peace operations to return the country to stability. The AMIS could also not get the support of both the government and the rebels. Worse still, the AMIS did not have the overwhelming presence or the necessary capabilities to fulfill its mandate. In Somalia, the AMISOM (deployed in 2007) also made very little impact, especially because of accusations of partiality against the AU, which was said to have aided Ethiopia to impose an illegitimate government on the people of Somalia. The AMISOM operations also had the challenge of limited number of troops over a vast area of operation.

On the management of Unconstitutional Changes of Government (UCGs), the AU, through the APSA, has shifted from the OAU days of condoning and working with unconstitutional governments. Except for a few cases, the AU appears to have outlawed UCGs, both on paper and in practice. UCGs recorded by the APSA so far include Togo (2005), Mauritania (2005 and 2008), Guinea (2008), Madagascar (2009), Niger (2010), Libya (20II), and Ivory Coast (20II). Again, in this area, the APSA has not been consistent in its application of the appropriate principles and norms, and for that matter sanctions. In some cases, the AU went out rightly to condemn the UCGs. However, in others, it delayed until after condemnation by other regional bodies such as the ECOWAS, only for it to add its voice in an indirect manner. This has led to accusations of partiality in response to UCGs leveled against the AU. The AU did not come out clearly to condemn the change in the Constitution of Niger by President Mamadou Tandja to allow him further stay in power. However, when the 2010 coup occurred in Niger, the AU was very quick to condemn it. Again in Ivory Coast, the AU delayed and never imposed sanctions on the President Gbagbo government for refusing to relinquish power after the defeat. Zimbabwe has been another dent on the legitimacy of the APSA, as the AU has been opposed to the imposition of sanctions against the Robert Mugabe regime. Appiah draws attention to the fact that although democracy has been accepted as the legitimate form of government in the continent, opposition parties also rarely win elections. Instead, some incumbents have won elections under questionable conditions but have faced no sanctions from the AU and its PSC. She also points to the fact that the APSA was not equipped with the requisite mechanisms to deal with the uprisings in Egypt and Tunisia, as well as the armed insurrection in Libya. The Libyan case, she posits, saw the AU being blatantly sidelined in the North Atlantic Treaty Organization (NATO) moves to oust the Muammar Gaddafi regime in Libya. This is evidence of a clash among the institutions of the UNSC and the AU and its PSC. Clearly, the APSA's application of AU 
norms on UCGs shows a lot of inconsistencies that need to be addressed to redeem the image of the $\mathrm{AU}$ and the legitimacy of its actions to bring peace and security.

\section{Conclusion}

In sum, the APSA has made great strides in delivering on its mandate to promote peace, security and stability in Africa. As hypothesized in the beginning of the paper however, the findings support the argument that the AU's inability to apply the rules, principles, values and norms of the AU in a uniform manner to shape the behaviour of Member States puts it at some disadvantage. Neo-institutionalism considers consistency in the application of norms crucial to the predictability of institutions. Again, it is only when there is predictability that continuity and change can be guaranteed. The APSA institution should be able to deliver the expected policy outcomes, that is, peace, security and stability in Africa. Until the many challenges of the APSA are dealt with, so as to put it in a formidable state to tackle all manner of conflict situations, the APSA cannot deliver on its mandate fully. Rather, its capacity and authority will be weakened with time, and would eventually have to fold up. The AU should develop and sustain a keen interest in the technical, human and financial resourcing of the APSA to enable it work optimally to deliver on its core mandate of promoting peace, security and stability in Africa.

After building its capacity to make it an independent institution capable of taking the right decisions for itself and acting pragmatically, the AU should build and strengthen the right partnerships with international organizations interested in peace, security and stability in Africa. This will place it in a position of being accepted and defended by its Member States (the insiders) as well as validated by the rest of the international community (the outsiders). 


\section{REFERENCES}

African Peace and Security Architecture. n/d. "African Union's blueprint for the promotion of peace, security and stability in Africa". http:// www.peaceau.org/uploads/african-peace-and-security-architecture-apsa-final.pdf.

African Union. 2000. "Lome Declaration of 2000 for conditions that qualify as unconstitutional changes of government". http://www.peaceau. org/uploads/ahg-decl-2-xxxvi-e.pdf.

. 2018. "Panel of the Wise (PoW)". http://www.peaceau.org/en/ page/29-panel-of-the-wise-pow.

. n/d. "Peace and Security Council". http://au.int/en.

. 2002. "Protocol relating to the establishment of the Peace and Security Council of the African Union".

. 2015. "The African Standby Force". http://www.peaceau.org/en/ page/82-african-standby-force-asf-amani-africa-I.

. 2000. "The Constitutive Act". Addis Ababa.

. 2018. "The Continental Early Warning Systems". http://www. peaceau.org/en/page/28-continental-early-warning.

Aning, Kwesi. 2008. "The UN and the African Union's security architecture: Defining an emerging partnership?'." critical currents 5: I7.

Appiah, Juliana Abena. 20I4. The African Union and the Quest for Peace and Security in Africa: 2002-2012. PhD diss., University of Ghana.

Bah, Alhaji Sarjoh; Choge Choge-Nyangoro; Solomon A. Dersso; Brenda Mofya, and Timothy Murithi. 20I4. The African Peace and Security Architecture: A handbook. Friedrich-Ebert-Stiftung.

Bell, Stephen. 2002. "Institutionalism." 363-380.

Fisher, L.M., et al. 20I0. "African Peace and Security Architecture (APSA) Assessment Study", 2010:33.

Murithi, Tim and Hallelujah Lulie. 20I2. "The African Union Peace and Security Council-a five-year appraisal." Institute for Security Studies Monographs no. I87: 268.

Pollack, M. A. 2008. "The New Institutionalisms and European Integration". Webpapers on Constitutionalism \& Governance beyond the State. 


\section{ABSTRACT}

The Africa Peace and Security Architecture (APSA) was instituted by the African Union (AU) in 2002 to uphold the AU's rules, norms, objectives and principles on peace, security and stability in Africa. The APSA was also established to ensure that the behaviour of AU Member States conformed to these principles and norms. The APSA was to be the operational structure for the effective implementation of decisions taken on conflict prevention, peace-making, peace support operations, peace-building and post-conflict reconstruction. Its mandate reflected the shift to human security, which is widely accepted at the continental level. The APSA has dealt with issues relating to human development; promote democratic practices, good governance and respect for human rights, humanitarian action and the management of disaster. Within the framework of the neo-Institutionalist theory of integration, and with the use of secondary data, this paper hypothesis that the APSA is disadvantaged as a result of not fairly applying its rules across the board in Member States. The paper assesses the performance of the APSA since its inception. The paper gives an overview of the major components of the APSA, its legal framework as well as its successes, prospects and challenges. The major objective of the paper was to ascertain whether the APSA has made any difference in the area of peace, security and stability in Africa since its establishment. The paper found that despite the great strides made by the APSA in delivering on its mandate to promote peace, security and stability in Africa, its inability to apply the rules, principles, values and norms of the AU in a uniform manner to shape the behaviour of Member States puts it at a great disadvantage. For the APSA to effectively deal with conflicts in Africa, it is recommended that the AU develops and sustains a keen interest in the technical, human and financial resourcing of the APSA to enable it work optimally. The African Union is encouraged to allow the rules to work and applied uniformly to member states when they default. The AU should also continue to build and strengthen its partnerships with international organizations concerned with peace and stability in Africa.

\section{KEYWORDS}

African Union; APSA; Conflict Resolution.

Received on March 8, 2018. Approved on June 6, 2018. 